\title{
COGNITIVE SELF-ENHANGEMENT AS A DUTY TO ONESELF: A KANTIAN PERSPECTIVE
}

\author{
KATHARINA BAUER
}

ABSTRACT: Recently some bioethicists and neuroscientists have argued for an imperative of chemical cognitive enhancement. This imperative is usually based on consequentialist grounds. In this paper, the topic of cognitive self-enhancement is discussed from a Kantian point of view in order to shed new light on the controversial debate. With Kant, it is an imperfect duty to oneself to strive for perfecting one's own natural and moral capacities beyond one's natural condition, but there is no duty to enhance others. A Kantian approach does not directly lead to a duty of chemical cognitive self-enhancement, but it also does not clearly rule out that this type of enhancement can be an appropriate means to the end of selfimprovement. This paper shows the benefits of a Kantian view, which offers a consistent ideal of self-perfection and teaches us a lesson about the crucial relevance of the attitude that underlies one's striving for cognitive self-improvement: the lesson of treating oneself as an end in itself and not as mere means to the end of better output.

\section{ENHANCE YOURSELF!}

Most people try to improve themselves in one way or another - they want to become more intelligent, more successful, more beautiful. And (hopefully) they also strive to become better friends, parents, citizens, and moral agents. In spite of on-going debates about the risks and moral concerns that are related to modern techniques of human

Katharina Bauer is a Feodor-Lynen fellow of the Alexander von Humboldt Foundation. Her primary areas of research are ethics and moral philosophy with a focus on the selfunderstanding and self-improvement of human beings. She is editor of a volume about Dimensions of Practical Necessity (Palgrave MacMillan, 2017) and the author of a book about theories of the gift (Alber, 2012) and several articles and book chapters about current issues of moral philosophy. 
enhancement, ${ }^{1}$ some bioethicists and neuroscientists argue that enhancements are not only permissible but should be regarded as an obligation for various reasons. They presuppose a general moral imperative of enhancement in order to improve the life of individual human beings or a more specific imperative to use chemical cognitive or emotional enhancers in order to contribute more efficiently to the goods and goals of a group or of society. Such imperatives of self-enhancement are usually based on consequentialist grounds. I will discuss the topic of cognitive self-enhancement - in particular the use of smart drugs in academia - from a Kantian point of view. Apart from few exceptions it is quite unusual to use Kantian arguments in this field of applied ethics. ${ }^{2}$ But Kant's theory offers new perspectives and helpful tools for analyzing the pros and cons and the moral status of cognitive selfenhancement in a surprisingly open-minded manner. With Kant, I will argue that there are good reasons to regard it as an imperfect duty to oneself - but not toward others - to advance one's own nature, personality, and moral perfection on the basis of critical self-reflection. And I will investigate what a Kantian approach can teach us about the appropriate means, the moral limitations, and the right reasons for selfenhancement.

After a short introduction into the practice of using smart drugs in academia and the risks that are related to chemical cognitive enhancement (section 2), I will briefly present recent positions that argue more or less explicitly for an obligation to enhance oneself (section 3). I will discuss the idea of a duty to enhance others (section 4) and point out the benefits of Kant's alternative understanding of self-improvement as a duty to oneself. It does not directly lead to a duty of chemical cognitive self-enhancement, but it also does not clearly rule out that this type of enhancement can be an appropriate means to the end of self-improvement (section 5). Nevertheless, a Kantian approach places limits on the use of such means (section 6). I will

\footnotetext{
${ }^{1}$ In this paper, enhancement is understood as an additional improvement beyond an already existing good quality. According to this definition, any kind of education aims at enhancement, but I will focus on methods of chemical cognitive enhancement. I accept the common distinction between therapy as the curing or restoring of dysfunctions and enhancement, which starts from a "normal" functioning in order to improve it (cf. Harris 2004, 44). However, there are probably borderline cases in which it is difficult to say whether the performance of a healthy or "normal" student is enhanced by the medication or whether a learning disorder is treated successfully.

${ }^{2}$ For a general discussion about the applicability of Kantian ethics see Altman 2011. I agree with Altman's presupposition that "Kant's philosophy deeply informs our moral thinking, so examining his approach to various topics in applied ethics will help us to reflect on and evaluate our own positions" (7). Few authors explicitly refer to Kant in discussing forms of enhancement (e.g., Gunderson 2007 and Meyers 2014).
} 
not conclude that the Kantian view provides answers to all the open questions of current debates about cognitive enhancement. But it offers a consistent ideal of self-perfection and teaches us the lesson of treating oneself as an end in itself and not as mere means to the end of better output (section 7).

\section{SMART DRUGS IN ACADEMIA: JUST LIKE DRINKING GOFFEE?}

It is reported that Kant drank a lot of coffee during his work. Surely, such a biographical note cannot serve as a serious philosophical argument, but it gives us a first hint at the fact that Kant may have showed sympathy for the idea of enhancing his mental capacities by using chemical substances. Of course, Kant's theory does not tell us anything about modern chemical enhancers. But in his Metaphysics of Morals he offers us a short but interesting passage about wine, spirits, and opium. Kant argues harshly against the use of drugs as far as they reduce intellectual capacities and make people act like animals or "cattle" and not like human beings. He introduces a negative perfect duty to oneself that is directed against "Stupefying Oneself by the Excessive Use of Food or Drink" (MM VI 427f). ${ }^{3}$ However, he asks whether a modest consumption of wine could be allowed for socializing or increasing one's virtues - in particular at the occasion of a banquet which is "a formal invitation to excess in both food and drink" to Kant's regret, but at the same time it has "a moral end" as "it brings a number of people together for a long time to converse with one another" (MM VI 428). ${ }^{4}$ In this passage, Kant very cautiously shows some agreement to the idea of using drugs as a means to a certain end - as long as it is a moral end.

Cognitive capacities are essential for moral improvement from a Kantian point of view. They are needed for any particular kind of development of one's talents as well as for sober rational reflection about one's maxims and ends. Understanding and applying the categorical imperative requires considerable cognitive efforts. With Kant, modern methods of chemical cognitive enhancement could thus be at least justified as contributions to one's moral enhancement. ${ }^{5}$ Still, one can actually presume that in scholarship and research chemical cognitive enhancement is usually not directly related to

\footnotetext{
${ }^{3}$ Kant's works are cited according to the standard pagination of the Berlin Academy edition [Akademieausgabe].

${ }^{4}$ It is surely open to discussion why and in so far this is a moral end in particular according to Kant's own understanding of morality. However, this question goes beyond the scope of this paper.

${ }^{5}$ For a more detailed discussion about the possibilities and problems of different forms of moral enhancement and its relation to cognitive enhancement, see Focquaert and Schermer 2015.
} 
moral ends. It is used with the intention to improve one's research, to learn more, to learn more efficiently, to improve one's results, or to gain competitive advantage.

So called "smart drugs" that are used for academic purposes have memory- and focus-boosting effects. They help persons to concentrate more efficiently on their work, even if a topic bores them, or they just help to keep them awake in order to prolong their overall working time. The risks of the use of CNS stimulants that were originally developed as treatments of ADHD, narcolepsy, and Alzheimer's, like Modafinil, Adderall, and Ritalin (Methyl-phenidates), as well as Ampakines, are often regarded as rather low. They do not easily cause physical addiction, even though they can clearly cause psychological addiction. And they can lead to a severe lack of sleep, which is dangerous for one's physical and psychological health. Nevertheless, it can be said that the scope of the positive and negative effects of the most common smart drugs does not really differ fundamentally from the consequences of harmless and well-established methods of cognitive enhancement-including biochemical methods like drinking coffee. Indeed, for many students and researchers the use of smart drugs is "just like drinking coffee." 6 They do not regard the higher degree of the effect of those enhancers as morally significant.

However, some studies suggest that the short-term advantage of improving one's cognitive performance has potentially high costs in the long run as it may reduce brain plasticity. A loss of plasticity can change a person's emotional setting and promote anxiety as well as "behavioral rigidity," and it can "potentially damage WM [working memory], logical thinking and decision making" (Urban and Gao 2014, 5). The focus on a concentrated short-term performance could probably diminish the capacity to plan ahead and to multitask. Some students report the individual experience of a loss of creativity and a loss of interest in non-work-related activities like social activities. The risk that short-term enhancement of particular cognitive capacities could be successful at the expense of long-term side effects that diminish the same or other important cognitive capacities is highly relevant for discussing the question whether chemical enhancements offer the right means to enhance oneself as a student or researcher. This also depends on which mental capacities should be enhanced. What is the right proportion between being focused and concentrated or open-minded and creative? Which kind of knowledge

\footnotetext{
${ }^{6}$ See the following reports: Deutsche Welle, "Smart Drugs: Generation Self-Optimization." Written by Caroline Schmitt. Last modified October 2014. http://dw.com/p/1DdmQ; Times Higher Education, "Pills Provide Brain Boost for Academics." Last modified June 2007. https://www.timeshighereducation.com/news/pills-provide-brain-boost-for-academics/209480. article.
} 
shall the enhanced student acquire - preferably broad or specialized knowledge? It remains open to discussion how to interpret the ideal of the perfect student or researcher. This hints at the relevance of a much more fundamental question: Which self would count as an "optimized," "perfected," or "enhanced self"? And what does it actually mean to "enhance" oneself?

Even though Kant is well aware of the fact that nobody is perfect, because human beings are not merely noumenal and reasonable, he introduces a clearly developed ideal of "one's own perfection" [eigene Vollkommenheit] (MM VI $386 f$ and 446). A perfect person would be perfectly reasonable and autonomous. She would set ends for herself in accordance with the moral law. In fulfilling her moral duties, she would always act from duty. Her only motive for acting morally would thus be correspondence to the moral law and it would not be contaminated or outperformed by any other motives like striving for pleasure or happiness. The ideal person would be able to govern her unsettled and contingent desires perfectly. For Kant, complete perfection cannot be completely realized by a single human being, but nevertheless each human being ought to strive after this ideal in order to contribute to the improvement of humanity.

As we will see later, Kant clearly holds the view that human beings ought to improve themselves beyond their natural disposition. Does that imply that they should make use of any available technological or biomedical means and developments of self-enhancement? The discussion about biomedical enhancement often refers to a difference between means of self-improvement "such as exercise" which are "considered natural and virtuous" and others that are "perceived as artificial" (de Grazia 2005, 206). Nevertheless, if it would be possible to develop smart drugs without any side effects, their use could probably be perfectly normal - just like drinking coffee or like the use of "artificial" means like glasses or binoculars to improve or enhance one's visual capacity (cf. Harris 2007, 19). It will probably become more and more normal to use chemical cognitive enhancers in the near future (cf. Bostrom and Sandberg 2009, 330). However, this does not automatically imply that it should be the norm. From a Kantian point of view, a reference to social conventions does not offer a sound normative argument. As the Kantian human being shall exceed its nature, the difference between natural and artificial means cannot be a decisive argument. When Kant deals with concrete methods of personal improvement he usually refers to rather classical methods of education. ${ }^{7}$ But Kant could have endorsed methods like genetic engineering

${ }^{7}$ He does so in his Methodology of Pure Practical Reason, in his Anthropology from a Pragmatic Point of View, as well as in his lectures on education. For a detailed discussion of Kant's theory of education, see Roth and Surprenant 2012. 
insofar as they can supplement education as well as "the cultivation of understanding and morally beneficial character traits" and contribute to a fulfillment of one's duty to oneself to seek perfection (Gunderson 2007, 88f). Let us now have a look at other arguments that are presented in favor of a norm or even imperative of chemical cognitive enhancement.

\section{A MORAL OBLIGATION?}

In a 2009 paper about cognitive enhancement Bostrom and Sandberg suggest developing "a culture of enhancement" (333). They ask why students should not be "positively encouraged to take performance enhancers (assuming they are sufficiently safe and efficacious) for the same reasons that they are encouraged to take notes and to start revising early" (328). They point out that the social force to enhance one's cognitive capacities is just equivalent to forcing literacy upon citizens of modern societies or to other measures of the educational system (ibid.). And they argue that some forms of cognitive enhancement can even contribute to a better development of autonomy "by enabling one to base choices on more deeply considered beliefs about unique circumstances, personal style, ideals, and the options available" (327). Hence, they suppose that there could be "a special obligation to help some incompetent subjects become competent agents capable of autonomous reasoning" (324) by means of cognitive enhancement. ${ }^{8}$

In an interview, Sandberg argues that self-enhancement shall not be regarded as cheating, because

competition is a zero-sum game: if one person uses enhancers, others have to do so too in order to have a chance. But in many jobs and higher education the actual situation is a positive-sum game: if we perform well, the group performs better.... The important part of universities is after all learning and thinking, and we want more and better learning and thinking." (Deutsche Welle 2014b)

From this point of view, the use of enhancers in academia is not only fair, it is a desirable contribution to the most essential task of the academic world. When Sandberg refers to the positive sum of better learning and thinking, he obviously introduces a consequentialist argument. He votes for the positivesum game in favor of the highest utility for the group.

Does that lead to an obligation to optimize our individual faculties in order to contribute more efficiently to the performance of the group and to the goal of "more and better learning and thinking"? Or does it even lead to a more general obligation to enhance yourself in order to enhance your

\footnotetext{
${ }^{8}$ I will discuss this argument in more detail in section 3.
} 
contribution to a better society, a better world or to the (highest) good? Some authors regard it as a professional duty to enhance particular capabilities in order to fulfill a particular function - like doing the work of a surgeon or a pilot ${ }^{9}$ or the work of a judge. ${ }^{10}$ Others argue that human beings should be morally enhanced in order to make sure that they do not misuse technologies and destroy their environment. ${ }^{11}$ Bioethicist John Harris actually recommends regarding enhancements in general as a moral obligation as "there are moral reasons ... to confer and not withhold even small benefits" for human beings (Harris 2009, 131). The overall goal that he presupposes is a healthy and long life without harm and suffering. He argues that parents should support the enhancement of their children (also by "buying educational privilege," Harris 2007, 27) and that "those of us who are autonomous enough to consider such questions, have good reasons to confer such benefits on ourselves" (Harris 2009, 132). It is one of Harris' main arguments in defense of enhancement that the difference between therapy and enhancement is usually overestimated. If human beings are always characterized by their natural deficiency, any kind of improvement turns into a therapy that corresponds to the moral imperative of preventing harm. This argument is transferable to an obligation to help "some incompetent subjects" (see above) in enhancing their autonomy and their capacities. As they are regarded as incompetent and deficient, this also blurs the differences between therapy and enhancement. And if a fundamental incompetence and deficiency is attributed to human nature as such, which is regarded as "a work-inprogress, a half-baked beginning that we can learn to remold in desirable ways" (Bostrom 2005, 4), this implies that we ought to remold ourselves as human beings or even transform ourselves into "transhuman" beings in order to prevent harm and confer benefit for humanity.

It sounds compelling to derive a moral obligation to enhance human beings from the aim of a better life. But the normative conclusion that "the morally justifiable enhancements owe their moral justification to the fact that they make lives better" (Harris 2009, 154) requires discussing what exactly makes a life better or worse. Is it the individual wellbeing of a person, the moral quality of her actions, or the contribution to a higher good, like the

\footnotetext{
${ }^{9}$ For an overview see Santoni De Sio et al. 2014. Goold and Maslen (2014) discuss whether chemical cognitive enhancement could be imposed on surgeons as a legal duty.

${ }^{10}$ See Sandberg et al. 2011. Chandler and Dodek (2016) discuss whether judges have an ethical obligation to use enhancements and whether their enhanced decision making would conflict with the views of the unenhanced public.

${ }_{11}$ The main proponents of this argument are Ingmar Persson and Julian Savulescu (2008; 2011; and 2013). The argument for moral enhancement in order to prevent climate change has also been defended by Matthew Liao, Anders Sandberg, and Rebecca Roach (2012).
} 
outcome of better learning and thinking for our society and culture? And it has to be discussed whether an obligation to improve oneself implies a duty to enhance others.

\section{A DUTY TO ENHANCE OTHERS?}

If an obligation to enhance oneself would be regarded as a duty in the strict sense, this could mean that others have a corresponding right to implement enhancement on someone - for example, on their own children. And if there was a right to live in a better world of better learning and thinking and a moral obligation to contribute to the overall improvement of this world, then this could lead to the idea that it was legitimate to institutionalize the implementation of cognitive enhancement - for example, by means of compulsory schooling as well as by means of incentivized programs for encouraging the use of chemical cognitive enhancers ${ }^{12}$ or even by introducing a legal duty. The principle that everyone should optimize himself in order to contribute to the high and unassailable goal of better learning and thinking sounds very attractive (at least to academics who obviously share this goal). However, if a duty of self-optimization gives others the right to urge persons to optimize themselves in favor of the performance of a group by means of social pressure, institutional interventions, or other influences like nudging, then the consequentialist interpretation of a normative principle of perfectionism opens the doors to many kinds of paternalism. Imagine a group of students who have to fulfill a task or write a thesis together. Those who take smart drugs in order to achieve a better result together can put strong social pressure on those who refuse to do so. They could blame them for hampering the optimal realization of the joint project. An institutionalized form of stipulating the use of smart drugs has a long tradition in the military, in particular for pilots. And in the view of those who favor a general enhancement of all the members of a society those who do not see a necessity to use particular means of enhancement can easily be regarded as incompetent minors who need to be necessitated with parental authority to take the newest and most extensive means of self-enhancement.

There is always a narrow ridge between assisting others in increasing their autonomy and reducing their autonomy through paternalist interventionin the peculiar tradition of forcing persons to be free (cf. Trachtenberg 2012). In principle, taking the maxim of fostering an agent's capacities in order to enable him to make his own autonomous decisions in the future is compatible with Kant as it means to respect the agent as a potentially

\footnotetext{
${ }^{12}$ Sarah Carter convincingly argues against the introduction of such incentives (2015).
} 
autonomous agent. However, for Kant it is most important to respect the other person as an end in herself and never to use her as a mere means to an end. More precisely one ought to respect the humanity in the person-in terms of her rational nature and her capacity of setting ends independently from her natural inclinations. Even if the fellow students or military pilots are respected as being competent in a specific area they are obviously used as a means to an end of a group. Still, it does not follow from this automatically that they are treated as mere means and not respected as ends in themselves. The reason why one decides to assist the other to enhance his human capacities can be based on respect, but it can also be based exclusively on the presupposition that one needs the enhanced version of the other as a useful instrument for realizing one's own ends or the ends of a group. Using a person - or, more precisely, the humanity in a person - merely as means can be defined as regarding and actively using her as an instrument in the service of reaching an end, without at the same time respecting her as an end in itself and without attaching importance to her consent. So it is also decisive here whether and to what extent the other really freely consents to using the method of enhancement or whether he rather gives in to pressure.

I would now like to suggest a Kantian way of thinking that allows us to keep the idealist imperative of self-improvement without accepting the consequences of social pressure or paternalistic interventions that could force individuals to use all available means to optimize themselves. Most of all this Kantian view is directed against the consequence that individual persons (learners) are treated or treat themselves as mere means to a common goal (the end of better learning). In order to understand this way of thinking let us now have a closer look at Kant's understanding of self-enhancement as a duty to oneself.

\section{5. "MAKE YOURSELF MORE PERFECT"-AN IMPERFECT DUTY TO ONESELF}

In his Metaphysics of Morals, Kant introduces the imperative "Make yourself more perfect than mere nature has made you" (MM VI 419). According to Kant, persons have duties to themselves ${ }^{13}$ - and not toward others - to preserve their own nature and to advance their personality and moral perfection beyond

\footnotetext{
${ }^{13}$ It is not self-evident that persons can have duties to themselves, but Kant defends those duties as the precondition for any duties to others (cf. MM VI 417f). The human being "can be put under obligation and, indeed, under obligation to himself (to the humanity in his own person)" (ibid.). There is an ongoing discussion about the possibility of such duties. To name just two exemplary contributions to that discussion, I would like to hint at Denis 1997 and Timmermann 2006.
} 
the conditions of their nature on the basis of critical self-reflection. I would like to underline two benefits of regarding self-improvement as a duty to oneself that can be extrapolated from a Kantian approach, which are relevant for discussing methods of chemical cognitive enhancement:

(1) A person cannot and ought not be necessitated by others to fulfill a duty that is a duty to herself. She owes her efforts of self-improvement to herself - respective to humanity in herself - but not to others. There is no duty to promote other's moral perfection according to Kant. So there is no good reason for paternalistic attempts to enforce methods of self-enhancement.

(2) There is latitude as to how exactly and to what extent the duty shall be satisfied in concrete actions and comportments. And there is latitude in the choice of specific ends (cf. Wood 2002, 168). Within the framework of rational end-setting, every person is free to decide which of her natural capacities she would like to develop, to what extent she is going to do so, and, especially, what means she is ready to use to improve her natural, mental, and moral capacities. It is thus not justified to establish a strict moral obligation, that is, a perfect duty to use enhancers in order to optimize one's capacities and output - either in academia or as a professional duty in other fields that were mentioned above.

(1) It is possible to support methods of chemical cognitive enhancement from a Kantian point of view, if they improve and do not reduce our intellectual capacities and if and only if they improve and do not reduce the person's capacity to set her own ends. Hence, any risk of physical or psychological addiction can provoke a serious objection against the use of smart drugs. Addiction restricts the free choice of ends, because it imposes a certain end on the agent and perpetuates it - the end of satisfying the addiction. The same concern about one's freedom of end-setting applies to social pressure or performance pressure and-as Kant is a strong antipaternalist (cf. Gunderson 2007, 97) — even more to institutional coercion that pushes people to self-enhancement. As Gunderson summarizes:

Kant claims that the perfection of a person is the ability to set one's ends in accord with one's conception of duty ... it follows that we cannot have a duty to seek the perfection of another person because only that person can set his or her own ends. (89)

One can hint at somebody the idea that self-perfection is an attractive goal, or one can make somebody aware of a particular ideal of human perfection. However, only the respective person can adopt the end as her own end. As setting oneself one's own ends in accordance with one's conception of duty is an essential element of the Kantian ideal of self-perfection - as well as of his conceptions of humanity and human dignity - it would be a logical contradiction to make a person set her own ends toward self-perfection. As a result, 
that person would finally miss the end of self-perfection. That is precisely why choosing the end of improving oneself as a person has to be understood as a duty to oneself. According to Kant, it would not make sense to introduce a duty of promoting the moral perfection of others. However, Lara Denis asks whether it is really logical that Kant denies this duty with an ought-impliescan argument, as he also knows that one cannot really perfect oneself, but he still argues that one ought to try it. She suggests introducing a wide duty to oneself of choosing the end to perfect others as far as they consent and also make their self-perfection their own end (cf. Denis 2001). This argument is comprehensible, however, the duty to others would then be a duty to assist them in their own attempts of improving themselves, according to their own free choice and according to their own ends. It can only follow after setting oneself the end of self-perfection, thus after the realization of the duty to oneself to adopt the maxim of striving for self-improvement.

(2) For Kant, a person owes it to herself to cultivate her natural talents and her moral capacity in terms of a "wide and imperfect duty" (MM VI [note], 444 and 446). Perfect duties are strict and narrow; imperfect duties allow for latitude "about that kind and extend of actions" (MM VI 446) that are, for example, undertaken to perfect one's natural capacities. However, it is most important that "a wide duty is not to be taken as permission to make exceptions to the maxim of actions" (MM VI 390). For Kant, it does not make sense to introduce a perfect duty of perfecting one's natural dispositions that would prescribe concrete actions, because "no rational principle prescribes specifically how far one should go in cultivating one's capacities (... in acquiring knowledge or skill)" (MM VI 392). He underlines that it is up to the individual who strives for self-improvement which natural talents to develop in which proportion. A human being should "choose [this] in accordance with his own rational reflection about what sort of life he would like to lead" (MM VI 445). And even the duty to cultivate one's morality, which is most important for Kant, is only a wide duty because "a human being cannot see into the depths of his own heart so as to be quite certain, in even a single action, of the purity of his moral intention" (MM VI 392), which is the decisive criterion of Kantian morality. So it is an imperfect duty toward oneself to choose the maxim of striving for self-perfection. This means that with Kant there is no duty to choose particular means to that end. And there is no good reason to argue for an obligation - for a perfect duty - that would stipulate the action of using cognitive chemical enhancers or other means of enhancement, even if a specific form of enhancement contributes to a desirable goal or if it could save the world because it could prevent negative consequences, like climate change (cf. Person and Savulescu, 2012). It can only be regarded as a wide duty to take the decision and choose the maxim of pursuing the 
enhancement of one's talents and improving one's morality. This is a duty of virtue and not a duty of right, which means that it is not enforced by "external constraint" but based on "free self-constraint" (AA VI 383).

But why do persons have to constrain themselves at all? Why do they have to put the duty on themselves to make themselves more perfect? Kant presupposes that human beings have a natural disposition toward selfcultivation, self-moralization, and self-civilization. Nevertheless, there is no automatism that guarantees the unfolding of these dispositions, because other dispositions and personal desires can impede their realization. However, persons are also essentially characterized by their capacities of committing themselves to overcoming these inner obstacles by imposing a corresponding duty on themselves. For Kant there is no duty to oneself to promote one's own welfare or happiness - or only in so far as this belongs to the necessary means to avoid temptations and to act morally (cf. MM VI 388). ${ }^{14}$ If good results or an academic career just correspond to someone's self-interest because they make him happy and fulfill his individual desires, these goals are not the right candidates to establish a duty to oneself. There is simply no need to establish a duty of better learning and thinking if someone already pursues these goals as contributions to his own happiness. A moral duty makes us independent from what we actually desire. It does not matter for Kant if we want better learning and thinking, or a healthier or longer or happier life, or if someone wants to be successful student and desires to gain that success as effortlessly as possible. It matters whether we should rationally will that end and whether we should therefore commit ourselves (as beings who are not purely rational) to these goals.

Kant presupposes that any "rational being ... necessarily wills that all the capacities in him be developed, since they serve him and are given to him for all sorts of possible purposes" (G IV 423). According to Robert Johnson, one of the decisive failures in conforming to this duty of self-improvement consists in being a "one-Dimensional person: She only aims to develop a capacity absolutely necessary to succeed at a single narrowly construed undertaking" (Johnson 2007, 142). One could ask whether Kant would really condemn a one-dimensional concentration on moral issues or on developing the talents of a moral philosopher. And as Kant's ideal of self-perfection implies "cultivating one's faculties ... the highest of which is understanding" (MM VI 387), it is most essential to develop one's cognitive capacities. The capacities of better learning and thinking serve human beings for all sorts of possible purposes. The fundamental principle of all duties to oneself is to know and examine yourself, because you have to know the maxims on which you act in

\footnotetext{
${ }^{14}$ For a controversial discussion see Denis 1999 and 2001.
} 
order to act morally. In Kant's own words you ought to "know your heartwhether it is good or evil" and to gain "moral cognition of [your] self" (ibid.). The fundamental duty to oneself is being an innate judge of one's actions, thus making use of one's conscience (cf. MM VI 438). As stated above, Kant obviously presupposes a profound and sophisticated activity of thinking about oneself and one's motives, actions, and their legitimacy that is crucial to advance one's moral perfection. If chemical cognitive enhancers clearly improve these activities of thinking and moral cognition, there would be good reasons to use them as means to better fulfill the duty to oneself to strive for self-perfection.

Is chemical cognitive enhancement compatible with the rational will of improving one's talents most completely? Finite beings cannot optimize all their capacities and talents. They always have to face a trade-off between different options of improving themselves. And the option of improving one's general cognitive capacities is obviously attractive within a Kantian framework. However, in the light of the discussion about possible effects and side effects of smart drugs, it does not seem clear whether chemical cognitive enhancers help to extend the scope of talents that can unfold within a limited timespan or whether they enforce a tendency toward being focused on only one goal and activity and, thus, a tendency toward one-dimensionality. If a method of chemical cognitive enhancement fosters one-sidedness because it leads to a restricted focus on one's work, a loss of interest in other activities, a loss of creativity, or a loss of brain plasticity, this would restrict the unfolding of all the capacities of a person.

But most of all, the maxim behind the decision to use a technique of selfenhancement is decisive: if a person is taking smart drugs with the one-sided prudential maxim to learn what is absolutely necessary for passing an examination and getting a good grade, and if she does not consider which further aspects of learning would help her to advance a more complete and, particularly, a moral self-development, this would be a failure and an infringement against the Kantian duty to oneself to strive for perfection - or at least a severe misunderstanding of that duty.

After all, the imperfect duty to oneself to adopt the maxim of striving for self-perfection does not lead to the duty to act on that maxim by means of chemical cognitive enhancement. Still, this does not imply that using these means could not be an appropriate and legitimate way of enforcing one's self-improvement from a Kantian point of view. As stated above, Kant's moral philosophy is not incompatible with modern methods of self-enhancement, but it also places limits on the use of such methods. 


\section{LIMITS THAT ARE PLACED ON ENHANGEMENT WITH KANT}

So far the risk of addiction as well as a possible fostering of one-sidedness have been pointed out as side effects of chemical cognitive enhancement that are problematic from a Kantian perspective. I will now take up the three sorts of limits that Gunderson distinguishes with regard to genetic engineering in order to discuss the limits that Kant's moral philosophy places on the use of certain methods of enhancement more systematically. These limits concern (1) the risk of "undermining humanity," (2) the problem of "unjustifiable risks," and (3) the drawback of a restriction on "competitive advantage" (Gunderson 2007, 92f.).

(1) The risk of undermining humanity has a specific relevance in cases of genetic engineering or cybernetics. Such methods of enhancement entail much stronger and more permanent interventions into someone's personality or nature than chemical cognitive enhancement. ${ }^{15}$ With Kant the highest risk of undermining one's own humanity is the risk of treating oneself merely as means to an end instead of respecting oneself at the same time as an end in itself and thus as a person. I will come back to the relation of that risk to a particular attitude toward oneself and to self-respect in the last section.

Furthermore, one could argue that any influence on a person's autonomy in the strict Kantian sense, as well as in a broader sense of being free to decide which sort of life you would like to lead, could undermine the humanity in a person. A Kantian position must give special consideration to any concerns about autonomy, which are generally important for questions of enhancement: Is the choice of a method of self-enhancement "sufficiently voluntary" with regard to "the social forces" that may have influenced the decision (de Grazia 2005, 221)? Does a student or researcher mainly react to peer pressure or to time and performance pressure? Or is it his own autonomous and elaborated decision to use a particular technique of enhancement?

Realizing one's autonomy, one's capacities of being reasonable and corresponding to morality are the main goals of any kind of self-improvement of human beings and ought not to be risked by the side effects of the means that are used or by the way in which the decision to use those means is formed or influenced. As Timmons points out, "one way in which one can

\footnotetext{
${ }^{15}$ There are strong concerns that through the use of such means of self-enhancement "we risk 'turning into someone else', confounding the identity we have acquired through natural gift cultivated by genuinely lived experiences" (The President's Council on Bioethics 2003, 300). With regard to our example we could ask: Is the enhanced person the same person, if a lazy, slow, and uninterested student suddenly turned into an eager beaver after he had used smart drugs?
} 
fail to respect his or her own humanity is to destroy or cause serious damage to those rational powers that constitute one's end-setting capacity" (2017, 192). With Kant the rational powers that distinguish human beings from animals constitute the capacity to set moral ends for oneself. However, one can also argue that the human person is characterized by a broader manner of developing her capacities and setting herself ends (cf. Johnson 2011). So far it is questionable to what extent smart drugs really help individuals to "base choices on more deeply considered beliefs" (see above) and foster their personal autonomy and an unfolding of their end-setting capacities or whether they rather foster a tunnel vision in pursuing particular objectives. A longterm loss of brain plasticity or long-term damage of cognitive capacities could definitively "cause serious damage to those rational powers that constitute one's end-setting capacity."

The Kantian ideal of the perfect person that is "worthy of the humanity that dwells within him" - the humanity "by which alone he is capable of setting himself ends" (MM VI 387) - is limiting the use of means of self-enhancement. However, with regard to the concrete question, whether a student or researcher should take smart drugs in order to improve his learning and thinking, if this is his own decision, corresponds to his own ends, and does not undermine his self-respect as a person, the concrete limits that are placed by this ideal depend on the risks and side effects.

(2) Does Kant's theory offer a clear answer to concerns about unjustifiable risks and side effects of enhancement methods? In his system of duties, the perfect duties to oneself with regard to one's animal nature are directed toward self-preservation. Persons have to care for their health and physical fitness. They ought not mutilate themselves, which cannot only be understood materially in terms of "depriving oneself of certain integral, organic parts," but also formally in terms of "depriving oneself (permanently or temporarily) of one's capacity for the natural (and so indirectly for the moral) use of one's powers" (MM VI 421). Thus, severe physical side effects of enhancers as well as the involved risks to reduce any of one's capacities immediately or in the long run have to be avoided. As self-preservation is a perfect duty to oneself, the negative duty not to self-harm one's animal nature is overriding the imperfect duty of self-improvement in Kant's system of duties. The fact that Kant expresses his disapproval of the vaccination against smallpox may be interpreted as a strong resistance against any risks and side effects of medical treatment. However, Kant was convinced that the vaccination entailed the risk of putting one's life in danger. Actually, it was a risky "inoculation with human smallpox (variolation) and not the vaccination with the less virulent cowpox" at that time (Unna 2003, 465). There is an ultimate limit of any risk-taking for Kant, which is "the categorical prohibition of self- 
destruction" (462). Self-preservation is a duty to oneself because it is the necessary condition for any striving for self-perfection and for realizing and optimizing one's rational and moral capacities. Fulfilling the imperfect duty of striving for self-perfection is meritorious, but nobody can be blamed for a lack of effort, because it is too difficult to evaluate this effort. However, violating the perfect duty of self-preservation is clearly a reason to blame someone - at least if he risks his life and his rational and moral capacities knowingly. Still, as Gunderson points out, risks "can be justifiable when carried out to ... further one's ability to act in accord with morally justified ends" (Gunderson 2007, 93). It remains delicate to detect which side effects are severe enough and which of them are documented well enough to uphold the argument of overridingness in practice. Again, the answer depends on a sober empirical investigation of the strength, the exact quality, and the frequency of particular risks and side effects.

(3) Concerns about competitive advantage, inequality, and cheating play a very prominent role in current debates about chemical cognitive enhancement. However, it is unclear how relevant positional advantages and inequality really are. Given that the access to smart drugs was equally unproblematic for each student, there would be equal competition. This would also mean that the competitors would "bear the expenses and other personal costs ... without gaining a competitive advantage" (de Grazia 2005, 218).

Thirty-three percent of Ivy League students who admitted to having used smart drugs in a 2014 U.S. survey did not regard their behavior as cheating (cf. APA 2014). But other studies show "that lay people have a generally negative view about enhancement" (Santoni de Sio et al. 2016, 19); just like doping in sports, the use of drugs instead of mere training and learning is often regarded as unfair. ${ }^{16}$ However, chemical enhancement can also be regarded as a variant of more common techniques of training and learning. According to a consequentialist view it is clear that though "positional advantage" of those who use enhancers may "constitute a moral disadvantage of their use," it is at the same time "doubtful ethics to deny a benefit to any until it can be delivered to all" (Harris 2007, 30 and 28).

Many authors who try to mitigate concerns about fairness or cheating hint at the noncompetitive essence or goal of scholarship and science, often in comparison to doping in sports. ${ }^{17}$ They refer to the academic world as a

\footnotetext{
${ }^{16}$ One of the main proponents of this criticism in the philosophical debate is Francis Fukuyama (2002).

${ }_{17}$ Several authors underline that the question of fairness depends on the rules and purposes of a particular social practice (cf. Roache 2008; Schermer 2008).
} 
particular social practice with particular rules. But it is a fact that competition for good results and a successful career do actually play an important role within this practice. Nevertheless, from a Kantian perspective it is not decisive whether competition is a part of the academic world, but whether it is a part of the maxim of the individual agents that interact in that world or not. "Adopting the maxim" to use enhancers "to obtain a competitive advantage over one's rivals would be volitionally inconsistent when willed to be universal law" (Gunderson 2007, 93). It thus conflicts with the first formula of Kant's Categorical Imperative. ${ }^{18}$ Furthermore, a person who strives for self-perfection in order to fulfill her duty to herself as a person will not form the maxim of enhancing herself in competition with others. However, this does not solve the problem that she may still profit from a competitive advantage and thus foster social inequality.

\section{A KANTIAN LESSON}

After all, Kant's theory of self-improvement as an imperfect duty to oneself does not offer simple answers to the question whether smart drugs are appropriate means to the end of self-perfection or to the question of which specific means would be appropriate. As imperfect duties allow for latitude, the question of how the maxims that are formed according to these duties are to be applied in particular cases has to be answered by casuistry, which is always a tricky business (cf. Unna 2003, 455). But there is a clear lesson that can be learned from Kant: a lesson about our maxims or, in other words, about the high relevance of the attitude, which underlies one's striving for selfoptimization.

Can concerns about social conformism be attenuated if a student decides to optimize himself (and chooses means to that end) because he thinks he owes this to himself and not because of social pressure? There are concerns that the use of smart drugs in academia can increase "Complicity with Morally Problematic Social Norms" and foster "Social Quietism" (de Grazia 2005, 215 and 217). Students or researchers who make use of cognitive enhancements for optimizing their individual performance indirectly support social norms of high-performance and high-output. Do they just correspond to the human capacity of "evolutionary adaption" to their environment (Bostrom and

${ }^{18}$ This is how Chris Meyers argues (2014). After all, he comes to the conclusion that the positive influence of the activities of athletes in sports on society, like giving examples of selfless teamwork and fairness, would be compromised by the use of enhancements and doping, but "the activities of scientists, scholars, and artists . . . , when successful, provide benefits to society that do not depend on the means with which their products are produced" (295). However, this is a consequentialist and not a Kantian argument. 
Sandberg 2009, 324)? The academic environment is not given by nature but man-made, and it can be modified actively by the social agents who are part of this environment. If the smart drugs make students and researchers able to manage their work efficiently and to complete their studies successfully even under problematic circumstances (like underfinanced universities, bad or unfair working conditions) they will probably see no reason why they should try to change those circumstances. It is not self-evident that a student with a Kantian attitude would be more attentive to problematic social or institutional conditions of his enhanced performance. But if a person understands that she first of all owes her self-improvement to herself or to the humanity in herself, but not to others or to society, consistency with social norms will not be her main motivation. If she decides to enhance her cognitive capacities, she will do it for herself, treating herself as a person, thus as an end in itself.

Still, Kant does not presuppose a solipsist ideal of self-perfection without any contribution of the individual person to the goals of society, to "the performance of the group" - or in more Kantian terms to the performance of humanity. According to Kant it is an imperative to perfect one's own talents, because we cannot rationally will a world in which no one does so. ${ }^{19}$ As Johnson points out, "the complete perfection of all individual human capacities would be something left for the totality of humanity to achieve in the fullness of time," which means that "the obligation to perfect ourselves is in fact an obligation to 'do one's part' toward this joint task of humanity as a whole" (Johnson 2007, 133f). Where then is the difference from the consequentialist position? Kant refers to utility when he says, "a human being has a duty to himself to be a useful member of the world," but he adds: "since this also belongs to the worth of humanity in his own person, which he ought not to degrade" (MM VI 446). The individual is not regarded as a part of the sum of the worth of humanity (or, in Sandberg's terms, as a part of the positive sum of the game of academic research). On the contrary, the whole sum of the worth of humanity is concentrated in each individual human being. It is the task of each person to align herself towards perfection - to the goal of unity and completeness of reason (cf. Kleingeld 2017). This goal is inscribed into her own nature as a rational and potentially reasonable human being. There is a difference between understanding one's striving for self-perfection as a minor contribution to the complete perfection of the totality of humanity or understanding it as something that one owes to oneself because of being a human being. The decisive difference of the Kantian perspective on selfimprovement is neither on the means nor on the social practice or culture. It is the maxim of your individual course of action and the stance that you take

\footnotetext{
${ }^{19}$ Cf. G IV 423 and Johnson 2007, 133.
} 
up for yourself that makes the difference. Doing what one owes to oneselfto one's nature as a human being - can be interpreted as being fair to oneself. And as the capacity to establish and fulfill duties to oneself is the condition to fulfill duties toward others according to Kant, this is an important prerequisite of being fair to others.

In Kant's theory of personality, self-respect - respect toward one's rationality, autonomy, and the self-imposed moral law - is most important. Selfrespect [Selbstachtung] is not to be confused with self-love or self-indulgence. It is positive self-perception that goes hand-in-hand with the experience of mastering one's inclinations and desires. Moral self-improvement will thus raise a person's self-respect. Accordingly, the ways in which someone fulfills his duties to himself by preserving and improving his nature as well as his moral capacities can be regarded as "ways in which a person comes to a realization of his own self-worth" (Paton 1990, 223). This self-worth as a person-one's dignity - is the reason why the person has to treat herself (as well as any other human being) as a person, which means, according to the Formula of Humanity of the Categorical Imperative [CI 2], never to treat the humanity in oneself (or others) as a mere means, but always at the same time as an end (cf. G IV 429). As Thomas Hill points out, "if one respects the moral law, then one must respect one's own moral rights" (Hill 1973, 98).

On the basis of these assumptions about one's relation to one's own status as a person, enhancements shall not compromise one's self-respect. De Grazia speculates "that if actions of this sort [i.e., enhancements] are morally problematic, that is because they demonstrate insufficient selfrespect" (de Grazia 2005, 241). A person who feels the need to use chemical cognitive enhancers could thereby demonstrate that she does not sufficiently respect her present rational capacities. However, I think it is more problematic that the decision to make use of such enhancers does not already demonstrate insufficient self-respect, but it can result in a loss of self-respect for one's performance.

Is it easier to respect one's own performance of better learning and thinking if it is more truly one's own achievement, because it is carried out without the support of chemical enhancers? For Meyers, enhancement is permissible "as long as the enhancements are only helping practitioners to do their own work and not doing the work for them" (Meyers 2014, 297). He indirectly refers to an ideal of authorship, of being the original source of one's own success and one's academic products. However, he points out that someone who takes enhancers to write a better book (for example, about Kant) will still have to write that book. Enhancers do not do the work for the agent. But I agree to the argument that "there is a grain of truth behind the responsibility-shifting justification" of the thesis that there should be less 
praise for enhanced performance (Santoni de Sio et al. 2016, 36): The activity - passing an exam - may still be the activity of the agent; nevertheless, in many cases we probably need a different description of the activity - passing an exam without medical aid or under the influence of chemical cognitive enhancers. At first sight the difference between these activities is analogous to the difference between the activities of writing and revising a whole book by hand with an old-fashioned typewriter or with a modern computer. However, in this case it is a difference within the mental capacities of the agent, and it thus probably has a greater impact on the way he can see and respect himself and his own mental activity of learning and thinking. And, furthermore, the degree of self-respect that accompanies these activities again depends on the maxim of the agent and not only on the means that he uses: Does he regard his activity of learning and thinking as a mere means to the end of enhancing his career, of contributing to common goals, or does he worship these capacities as essential elements of himself being a rational human being?

Johnson asks: "If there is something suspect about a failure to improve yourself, is the fault only that you have somehow wronged others in some way, say, by not being as useful to others as you should be?" (Johnson 2011, 1). From a Kantian point of view the fault is rather that you have somehow wronged yourself - namely, yourself as a person, who shall not primarily be treated as being useful either for someone else or for society or for a higher goal - so, "what makes it wrong is that you have failed to respect your own humanity" (Johnson 2007, 125). In the discussion about the appropriateness and status of chemical cognitive self-enhancement, the following lesson can be learned from Kant: it is crucial not to regard and treat oneself as a mere means for better output. Understanding self-improvement as a duty to oneself, as something that each person owes to herself, includes respecting oneself (and, correspondingly, the other) as a person - who is capable of development; who is able to develop from within herself; who is free to decide which means to use or to refuse for her self-improvement; who shall not be pushed or forced from outside to cultivate and improve herself, though she may surely be invited and supported to do so. Kant's duties to oneself request that one treats oneself as well as any other human being as a person and thus as an end in itself. ${ }^{20}$

${ }^{20}$ I would like to thank Pauline Kleingeld and other discussants at the Rijksuniversiteit Groningen as well as Heidi Samuelson and two anonymous reviewers for their very insightful comments on this paper. I am also grateful to the Alexander von Humboldt Foundation for the support of my research about a Kantian perspective on self-enhancement. 


\section{REFERENCES}

Altman, Matthew C. 2011. Kant and Applied Ethics: The Uses and Limits of Kant's Practical Philosophy. Oxford: Wiley-Blackwell.

American Academy of Pediatrics (APA). 2014. "Many Ivy League Students Don't View ADHD Medication Misuse As Cheating." Last Modified May 2014. https://www. eurekalert.org/pub_releases/2014-05/aaop-mil042514.php.

Bostrom, Nick. 2005. "Transhumanist Values." Fournal of Philosophical Research 30 (Suppl.): 3-14.

Bostrom, Nick, and Anders Sandberg. 2009. "Cognitive Enhancement: Methods, Ethics, Regulatory Challenges." Science and Engineering Ethics 15, no. 3: 311-41.

Carter, Sarah. 2015. "Putting a Price on Empathy: Against Incentivising Moral Enhancement." Journal of Medical Ethics 41, no. 10: 825-29.

Chandler, Jennifer, and Adam Dodek. 2016. "Cognitive Enhancement in the Courtroom. The Ethics of Pharmacological Enhancement of Judicial Cognition." In Cognitive Enhancement: Ethical and Policy Implications in International Perspectives, edited by F. Jotterand and V. Dulljevic. 329-44. Oxford: Oxford University Press.

DeGrazia, David. 2005. Human Identity and Bioethics. Cambridge: Cambridge University Press.

Denis, Lara. 1997. "Kant's Ethics and Duties to Oneself." Pacific Philosophical Quarterly 78, no. 4: 321-48.

. 1999. "Kant on the Perfection of Others." Southern Fournal of Philosophy 37, no. 1 (March): 25-41.

- 2001. Moral Self-Regard: Duties to Oneself in Kant's Moral Theory. New York/London: Garland.

Deutsche Welle. 2014a. "Smart Drugs: Generation Self-Optimization." Written by Caroline Schmitt. Last modified October 2014. http://dw.com/p/1DdmQ.

—. 2014b. "Oxford Academic: I Use Brain Enhancing Drugs." Written by Caroline Schmitt. Last modified October 2014. http://dw.com/p/1DdnR.

Focquaert, Farah, and Maartje Schermer. 2015. "Moral Enhancement: Do Means Matter Morally?” Neuroethics 8, no. 2: 139-51.

Fukuyama, Francis. 2002. "Our Posthuman Future": Biotechnology as a Threat to Human Nature. New York: Farrar, Straus \& Giroux.

Goold, Imogen, and Hannah Maslen. 2014. "Must the Surgeon Take the Pill? Negligence Duty in the Context of Cognitive Enhancement." Modern Law Review 77, no. 1 (January): 60-86.

Gunderson, M. 2007. "Seeking Perfection: A Kantian Look at Human Genetic Engineering." Theoretical Medicine and Bioethics 28, no. 2: 87-102.

Harris, John. 2007. Enhancing Evolution: The Ethical Case for Making Better People. Princeton: Princeton University Press.

Harris, John 2009. "Enhancements Are a Moral Obligation." In Human Enhancement, edited by Julian Savulescu and Nick Bostrom, 131-54. Oxford: Oxford University Press.

Harris, John. 2011. "Moral Enhancement and Freedom.” Bioethics 25, no. 2 (February): 102-11. 
Hill. Thomas E. 1973. "Servility and Self-Respect." Monist 57, no. 1 (January): 87-104. Johnson, Robert N. 2007. "Self-Development as an Imperfect Duty." In Essays on the Development of Character and Virtue: Moral Cultivation, edited by B. K. Wilburn. 125-46. Plymouth, UK: Lexington Books.

- 2011. Self-Improvement. An Essay in Kantian Ethics. Oxford: Oxford University Press.

Kant, Immanuel. 1996. The Metaphysics of Morals, edited by M. Gregor. Cambridge: Cambridge University Press.

- 2002. Groundwork for the Metaphysics of Morals, edited by Allen Wood. New Haven, CT: Yale University Press.

Kleingeld, Pauline. 2017. "Kant on 'Good', the Good, and the Duty to Promote the Highest Good." In The Highest Good in Kant's Philosophy, edited by Thomas Höwing, 33-50. Berlin: De Gruyter.

Liao, Matthew, Anders Sandberg, and Rebecca Roache. 2012. "Human Engineering and Climate Change." Ethics, Policy \& Environment 15, no. 2: 206-21.

Meyers, Chris D. 2014. "Neuroenhancement in Reflective Equilibrium: A Qualified Kantian Defense of Enhancing in Scholarship and Science." Neuroethics 7, no. 3: 287-98.

Paton, Margaret. 1990. "A Reconsideration of Kant's Treatment of Duties to Oneself." Philosophical Quarterly 40, no. 159: 222-33.

Persson, Ingmar, and Julian Savulescu. 2008. "The Perils of Cognitive Enhancement and the Urgent Imperative to Enhance the Moral Character of Humanity." Gournal of Applied Philosophy 25, no. 3 (August): 162-77.

. 2011. "Unfit for the Future? Human Nature, Scientific Progress, and the Need for Moral Enhancement." In Enhancing Human Capacities, edited by Julian Savulescu, Ruud ter Meulen, and Guy Kahane, 486-500. Oxford: WileyBlackwell.

- 2013. "Getting Moral Enhancement Right: The Desirability of Moral Bioenhancement." Bioethics 27, no. 3: 124-31.

Roache, Rebecca. 2008. "Enhancement and Cheating." Expositions 2, no. 2: 153-56.

Sandberg, Anders, Walter Sinnott-Armstrong, and Julian Savulescu. 2011. "Cognitive Enhancement in Courts." In Oxford Handbook of Neuroethics, edited by Judy Illes and Barbara J. Sahakian, 273-284. New York: Oxford University Press.

Santoni De Sio, Filippo, Nadira Faulmüller, and Nicole Vincent. 2014. "How Cognitive

Enhancement Can Change Our Duties." Frontiers in Systems Neuroscience 8: 131. doi: 10.3389/fnsys.2014.00131.

Santoni de Sio, Filippo, Nadira Faber, Julian Savuelscu, and Nicole Vincent. 2016.

"Why Less Praise for Enhanced Performance. Moving Beyond ResponsibilityShifting, Authenticity, and Cheating Toward a Nature-of-Activities Approach." In Cognitive Enhancement: Ethical and Policy Implications in International Perspectives, edited by Fabrice Jotterand and Veljko Dulljevic, 27-40. Oxford: Oxford University Press.

Schermer, Maartje. 2008. "On the Argument That Enhancement is 'Cheating." Gournal of Medical Ethics 34, no. 2 (February): 85-88.

Timmermann, Jens. 2006. "Kantian Duties to the Self, Explained and Defended." Philosophy 81, no. 3: 505-30. 
The President's Council on Bioethics. 2003. Beyond Therapy: Biotechnology and the Pursuit of Happiness. Washington, DC: U.S. Bioethics Commissions Archival Collection.

Times Higher Education. 2007. "Pills Provide Brain Boost for Academics." Last modified June 2007. https://www.timeshighereducation.com/news/pills-providebrain-boost-for-academics/209480.article.

Trachtenberg, Zev. 2012. "Human Engineering and the Value of Autonomy." Ethics, Policy \& Environment 15, no. 2: 244-47.

Unna, Yvonne. 2003. "Kant's Answers to the Casuistical Questions Concerning Self-Disembodiment." Kant-Studien 94, no. 4: 454-73.

Urban, Kimberly R., and Wen-Jun Gao. 2014. "Performance Enhancement at the Cost of Potential Brain Plasticity: Neural Ramifications of Nootropic Drugs in the Healthy Developing Brain." Frontiers in Systems Neuroscience 8, no. 38. doi: 10.3389/ fnsys. 2014.00038

Wood, Allen. 2002. "What is Kantian Ethics?" In Groundwork for the Metaphysics of Morals, edited by Allen Wood, 157-81. New Haven: Yale University Press. 